\title{
Increasing obesity in treated female HIV patients from Sub-Saharan Africa: potential causes and possible targets for intervention
}

\author{
Claire L. McCormick ${ }^{1}$, Arianne M. Francis ${ }^{2}$, Kim Iliffe ${ }^{2}$, Helen Webb ${ }^{1}$, Catherine J. Douch ${ }^{1}$, Mark Pakianathan ${ }^{1}$ \\ and Derek C. Macallan ${ }^{1,2 *}$
}

Clinical Infection Unit \& Department of Genitourinary Medicine, St. George's Healthcare NHS Trust, London, UK

2 Infection and Immunity Research Institute, St. George's, University of London, London, UK

Edited by:

Frank Kirchhoff, University Clinic Ulm, Germany

Reviewed by:

Sarah Rowland-Jones, John Radcliffe Hospital, UK

Frank Kirchhoff, University Clinic UIm, Germany

\section{*Correspondence:}

Derek C. Macallan, Infection and Immunity Research Institute, St George's, University of London, Cranmer Terrace, London SW17 ORE UK

e-mail:macallan@sgul.ac.uk
Objectives: To investigate changing nutritional demographics of treated HIV-1-infected patients and explore causes of obesity, particularly in women of African origin.

Methods: We prospectively reviewed nutritional demographics of clinic attenders at an urban European HIV clinic during four one-month periods at three-yearly intervals (2001, 2004, 2007, and 2010) and in two consecutive whole-year reviews (2010-2011 and 20112012). Risk-factors for obesity were assessed by multiple linear regression. A sub-study of 50 HIV-positive African female patients investigated body-size/shape perception using numerical, verbal, and pictorial cues.

Results: We found a dramatic rise in the prevalence of obesity (BMI $\left.>30 \mathrm{~kg} / \mathrm{m}^{2}\right)$, from 8.5 (2001) to $28 \%(2011-2012)$ for all clinic attenders, of whom $86 \%$ were on antiretroviral treatment. Women of African origin were most affected, $49 \%$ being obese, with a further $32 \%$ overweight (BMI $25-30 \mathrm{~kg} / \mathrm{m}^{2}$ ) in 2012 . Clinical factors strongly associated with obesity included female gender, black African ethnicity, non-smoking, age, and CD4 count (all $P<0.001$ ); greater duration of cART did not predict obesity. Individual weight-time trends mostly showed slow long-term progressive weight gain. Investigating body-weight perception, we found that weight and adiposity were underestimated by obese subjects, who showed a greater disparity between perceived and actual adiposity $(P<0.001)$. Obese subjects targeted more obese target "ideal" body shapes $(P<0.01)$, but were less satisfied with their body shape overall $(P=0.02)$.

Conclusion: Seropositive African women on antiretroviral treatment are at heightened risk of obesity. Although multifactorial, body-weight perception represents a potential target for intervention.

Keywords: HIV, body weight, body mass index, obesity, antiretroviral treatment, ethnology, HIV-associated lipodystrophy syndrome

\section{INTRODUCTION}

When the HIV/AIDS pandemic emerged in the 1980's wasting represented the major metabolic consequence of the disease (1) and was recognized as an AIDS-defining criterion. The revolution in HIV care resulting from the introduction of combination antiretroviral treatment (cART) has been matched by dramatic improvements in nutritional status (2), although wasting remains problematic in some settings (3). Early treatment regimes were, however, associated with other metabolic sequelae, most notably HIV-associated lipodystrophy syndrome (HALS). The visceral adiposity associated with HALS is of particular concern because of its association with insulin resistance, diabetes, and cardiovascular disease, effects which may be compounded by the effects of cART itself $(4,5)$. The prevalence of HALS has declined markedly in recent years with changing patterns of drug use (6) but has been replaced by today's emerging metabolic problem, obesity (7-9). Obesity, which represents an entity distinct from visceral lipodystrophy (10), has recently been reported in several HIVpositive cohorts $(2,7,8,11,12)$. There is evidence that black African ethnicity and female gender increase the risk of weight gain on cART $(2,11,13,14)$, although most studies regarding African ethnicity have focused on African-American populations $(15,16)$.

If the enhanced risk of obesity among HIV-infected women of African origin is a real effect, several plausible mechanisms might be proposed. First, genetics are clearly pivotal $(17,18)$. BMI has been linked to specific chromosomal loci in two separate African-American populations (19) and resistin gene polymorphisms contribute to hyperlipidemia and insulin-resistance on cART (20). Polymorphisms in uncoupling proteins are linked to ethnicity $(21,22)$ and, specifically, variants of uncoupling protein3 with reduced basal metabolism in African-American women (23). Second, physiological adaptations occur with migration or environmental and dietary changes; adaptations to early-life 
limited nutrition may constitute maladaptations to later-life nutritional abundance $(24,25)$. More acute physiological adaptations occur with wasting syndromes; typically, on recovery an "overshoot" occurs with preferential recovery of adipose and delayed recovery of lean tissue in the early recovery phase, as demonstrated both in post-starvation re-feeding (26) and recovery from pulmonary tuberculosis (27).

Such genetic and physiologic determinants of body weight may, however, be less relevant in clinical practice for two reasons; first, they represent poor targets for intervention and, second, powerful cultural and ethnic drivers for body-weight change are superimposed upon and may over-ride them. Body image is a key determinant of "usual" weight and body-weight perception influences food intake. Widely held dogma suggests that women of African origin are likely to desire larger body sizes (28). Although evidence for this tenet is largely anecdotal, several studies support it. For example, Ugandan-born subjects in Britain rated heavier figures more positively than British natives (29), and African-Americans recorded greater satisfaction with body image and less anxiety regarding weight than comparable white American women (3032). Such attitudes can also be found among HIV-infected women. In one study, more seropositive African-Americans wished to be "bigger" than did non-African-Americans (32 versus 15\%) and more overweight participants perceived themselves as of "normal" weight (81 versus 50\%) (28). Such views are not limited to urban African-American communities. Qualitative studies in disadvantaged communities in South Africa found that increased body size represented a marker of well-being (33); furthermore, twothirds of adolescent women associated fatness with happiness and health (34). Not all authors endorse this simplistic paradigm; an urban Los Angeles study found no evidence that ethnicity influences preference for body shape or tolerance of obesity (35). If weight perception is a significant determinant, it represents a factor potentially amenable to intervention.

This paper reports a series of studies aiming, first, to test the hypothesis that obesity is an emerging clinical issue for HIV-positive patients on treatment (2); second, to investigate risk-factors for obesity in this population; and third, to explore how body-weight and body-shape perception relate to nutritional status and obesity among women of African origin.

\section{MATERIALS AND METHODS}

This study followed relevant institutional and national guidelines and regulations with the agreement of the Local Research Ethics Committee. The setting was a London (UK) tertiary-hospital HIV clinic.

To assess whether obesity is an emerging clinical issue for HIV-positive patients on treatment, clinical and nutritional demographic data were collected in two ways:

(i) Prospective one-month surveys, collecting nutritional and basic demographic data, were performed on all adult ( $\geq 18 \mathrm{y})$ HIV-clinic attenders in the month of February every 3 years from 2001 to 2010. [Some data have previously been published (2).]

(ii) Two consecutive whole-year surveys were performed in 2010$2011(n=1166)$ and 2011-2012 $(n=1031)$ in which extensive clinical data, including nutritional data, were collected. The data collection form was modified between the first and the second one-year survey, so each survey was analyzed separately. Repeat visits and pregnant patients (including $\leq 3$ months post-natal) were excluded. BMI was classified according to WHO descriptors: <18.5, wasted; $18.5-20$, underweight; 20-25, normal; 25-30, overweight; >30, obese (36). In order to assess how obesity had arisen in those with the highest BMI values, weight recordings were retrieved from the hospital notes of 30 consecutive obese African women with adequately complete records (representing $>180$ patient-years of drug exposure). Trends were analyzed descriptively, as in analogous HIV-wasting studies (37), and by linear regression to derive a rate of weight change per year.

To investigate the risk-factors for obesity, we analyzed the large ( $n>1000$ ) 2010-2011 and 2011-2012 cohorts, relating BMI to clinical parameters (listed below) by simple and multiple-stepwise regression. Preceding one-month cohorts were not analyzed in this way because of their smaller size. For a comparator "normal" population, we used the "Health Survey for England" data set, which includes BMI data on 11,022 UK residents, 5,443 of whom are classified by ethnicity (38).

The relationship between body-weight/shape perception and obesity was assessed in 50 adult non-pregnant African women using a structured questionnaire. Subjects were recruited consecutively from clinic attenders willing to participate, regardless of BMI (hence both obese and non-obese patients were included). The questionnaire was produced in-house after piloting preliminary drafts and included questions on weight history, treatment, perceived links between treatment and weight change, background history (country of origin), ability to identify other major cardiovascular risk factors (smoking, diabetes, hypertension, hypercholesterolemia, and family history of stroke/heart disease), and level of satisfaction with current weight on a Likert scale. Current perception of body shape/body weight was assessed in three complementary ways: (1) numerically in kilograms: subjects rated their "usual" and "ideal" weights (normalized to BMI for between-subject comparisons); (2) textually: identifying their current nutritional status in terms of WHO descriptors ("wasted, underweight, normal, overweight, obese"); and (3) pictorially using figural stimuli: subjects identified current and ideal body shapes using images of known adiposity. Two published series of silhouettes were used: one (Series A) consisted of seven silhouettes corresponding to specified BMI's; (39) the other (Series B), nine silhouettes of increasing adiposity, not calibrated by BMI (40). For body image scores, background comparator data were derived from published cohorts of 16,728 Caucasians (41) and 389 American women of mixed ethnicity (42).

Analysis of potential causes of obesity was framed around five putative hypotheses. Statistical comparisons were made by Fishers exact test and linear regression using Prism (GraphPad Software Inc., CA, USA) and Sigmaplot (Systat Software Inc., CA, USA).

\section{RESULTS}

\section{TIME-TRENDS IN NUTRITIONAL DEMOGRAPHICS}

One-month clinic datasets for nutritional demographics included $164,204,196$, and 373 subjects in 2001, 2004, 2007, and 2010 
respectively. Time-trends in BMI clearly showed an increasing prevalence of obesity over this period (Figure 1). This trend was most marked in women of black African descent; when each demographic group was considered separately (Figure S1 in Supplementary Material) this was the group most affected. In 2001, only $20 \%$ of black African women were obese, but this value increased progressively with each prospective three-yearly review, reaching $49 \%$ in 2012, a 2.5-fold increase in the prevalence of obesity over 10 years (Figure 1B). Male obesity also increased over the same time period, from 2 to $13 \%$, although resulting levels of obesity were less marked (Figure 1A). This observation was not due to major changes in the overall demographics of patients attending the clinic (Figure S2 in Supplementary Material).

Individual weight-time graphs for obese African women, all of whom were on cART, revealed several distinct patterns (Figure S3 in Supplementary Material). The dominant pattern was one of slow progressive weight gain over several years (12/30); others showed early weight gain followed by stabilization (9/30),

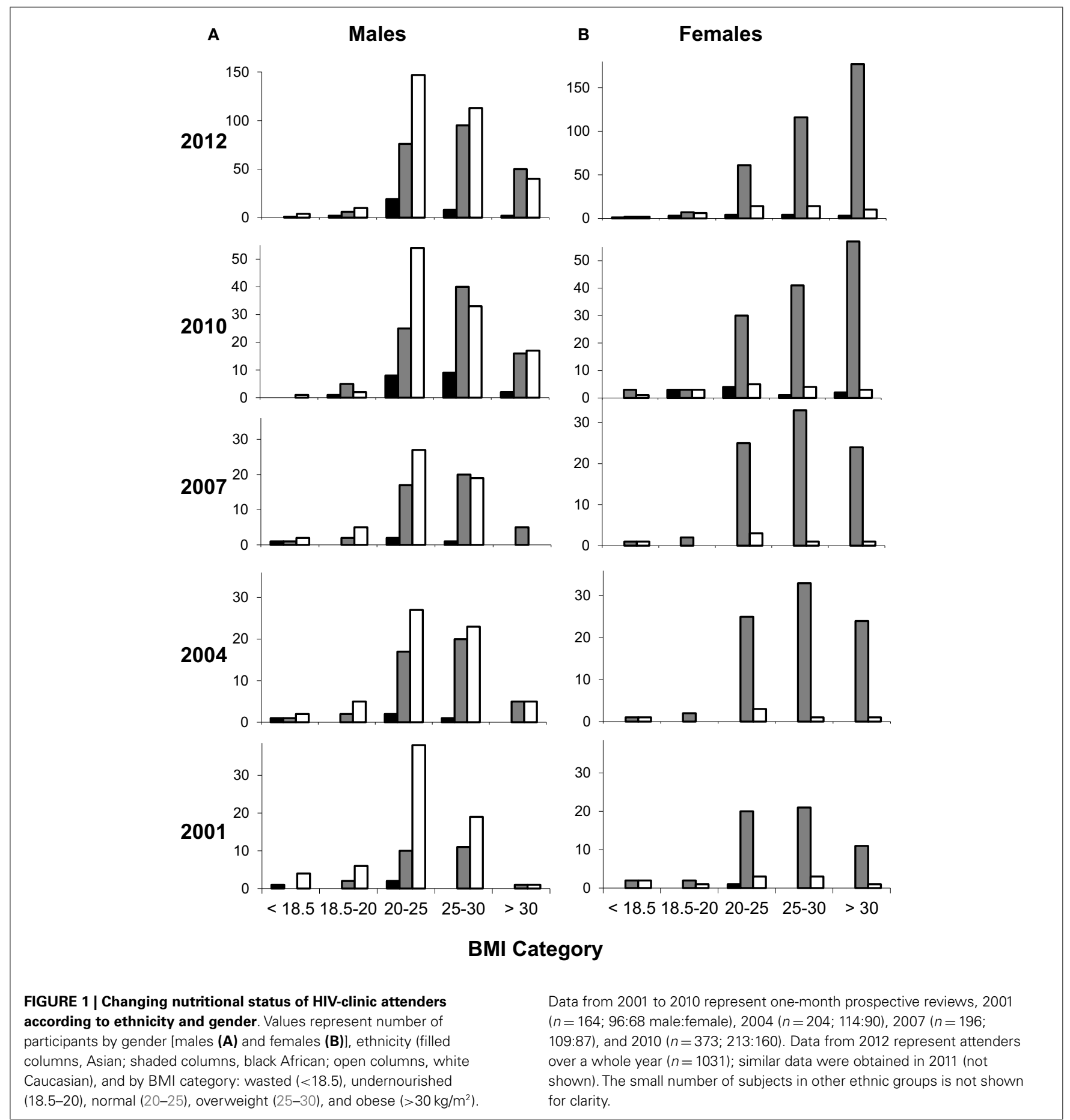


Table 1 | Weight trends of obese African women on cART by drug-class

\begin{tabular}{|c|c|c|c|c|c|c|}
\hline $\begin{array}{l}\text { Subject } \\
\text { reference }\end{array}$ & $\begin{array}{l}\text { NNRTI } \\
\text { exposure } \\
\text { (year) }\end{array}$ & $\begin{array}{l}\text { Cumulative } \\
\text { NNRTI effect } \\
\left(\mathrm{kg} / \mathrm{m}^{2}\right)\end{array}$ & $\begin{array}{l}\text { NNRTI trend } \\
\left(\mathrm{kg} / \mathrm{m}^{2} \text { year) }\right.\end{array}$ & $\begin{array}{l}\text { PI exposure } \\
\text { (year) }\end{array}$ & $\begin{array}{l}\text { Cumulative } \\
\text { PI effect } \\
\left(\mathbf{k g} / \mathrm{m}^{2}\right)\end{array}$ & $\begin{array}{l}\text { PI trend } \\
\left(\mathrm{kg} / \mathrm{m}^{2} \text { year }\right)\end{array}$ \\
\hline 2 & 0.00 & & & 4.51 & 2.29 & 0.51 \\
\hline 3 & 1.88 & 1.85 & 0.98 & 0.00 & & \\
\hline 6 & 0.00 & & & 2.63 & 2.80 & 1.06 \\
\hline 7 & 2.33 & -0.29 & -0.13 & 0.00 & & \\
\hline 8 & 2.93 & 1.60 & 0.55 & 9.11 & 2.15 & 0.24 \\
\hline 9 & 0.82 & 5.19 & 6.31 & 4.04 & 4.55 & 1.13 \\
\hline 10 & 11.15 & 4.61 & 0.41 & 1.57 & 1.88 & 1.19 \\
\hline 15 & 7.21 & 3.64 & 0.50 & 0.00 & & \\
\hline 16 & 5.21 & 5.54 & 1.06 & 0.00 & & \\
\hline 17 & 0.90 & 2.55 & 2.83 & 1.33 & 2.54 & 1.92 \\
\hline 18 & 1.50 & 2.65 & 1.76 & 0.00 & & \\
\hline 19 & 11.16 & 3.05 & 0.27 & 0.00 & & \\
\hline 20 & 13.02 & 4.21 & 0.32 & 0.00 & & \\
\hline 21 & 8.93 & 7.64 & 0.86 & 0.00 & & \\
\hline $22^{*}$ & 5.64 & 4.11 & 0.73 & 0.00 & & \\
\hline 23 & 1.11 & 0.11 & 0.10 & 0.00 & & \\
\hline 24 & 0.00 & & & 2.99 & 3.29 & 1.10 \\
\hline 25 & 1.42 & 3.26 & 2.29 & 15.12 & -0.59 & -0.04 \\
\hline Sum & 121.1 & 77.3 & 0.64 & 61.5 & 36.3 & 0.59 \\
\hline \multirow[t]{2}{*}{ All treatments } & Exposure & Cumulative effect & Trend & & & \\
\hline & 182.6 & 113.6 & 0.62 & & & \\
\hline
\end{tabular}

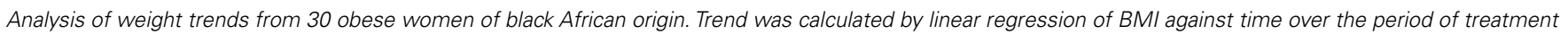

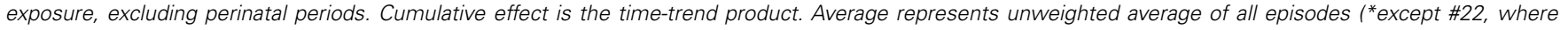

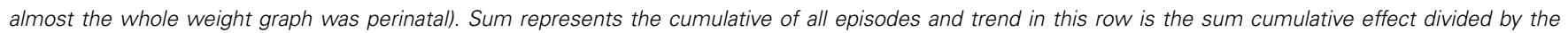
cumulative exposure, i.e., a weighted average.

and some, obese pre-treatment, remained obese (7/30). The average weight trend over 183 person-years of follow-up was $+0.62 \mathrm{~kg} / \mathrm{m}^{2}$ year (Table 1). Rates were similar in patients on NNRTI- and PI-based regimens (means 0.64 and $0.59 \mathrm{~kg} / \mathrm{m}^{2}$ year, respectively; $P=0.89$; Table 1 ).

\section{CURRENT NUTRITIONAL DEMOGRAPHICS OF HIV-CLINIC ATTENDERS}

Since sequential one-month audits included only limited numbers of subjects, whole-year audits were performed in 2010-2011 and 2011-2012. As expected from the substantial overlap between cohorts (977 patients in both), results were similar. Results from the most recent cohort only are therefore presented including 1,031 subjects with median age 44 (range 19-83). Although overall similar numbers of men and women were included, more men were white Caucasian $(314 / 599,52 \%)$, whilst most women $(84 \%)$ were of black African origin (363/432, including patients of black African extraction but more-recent Caribbean origin) (Table 2). Median CD4 was 500 cells/uL and $73 \%$ had an undetectable viral load.

Assessment of BMI (Table 2) showed striking levels of obesity, most prevalent in women of black African origin, of whom $49 \%$ $(177 / 363)$ were obese, with a further $32 \%(116 / 363)$ overweight. 
Table 2 | Distribution of BMI groups by gender and race among clinic attenders 2011-2012.

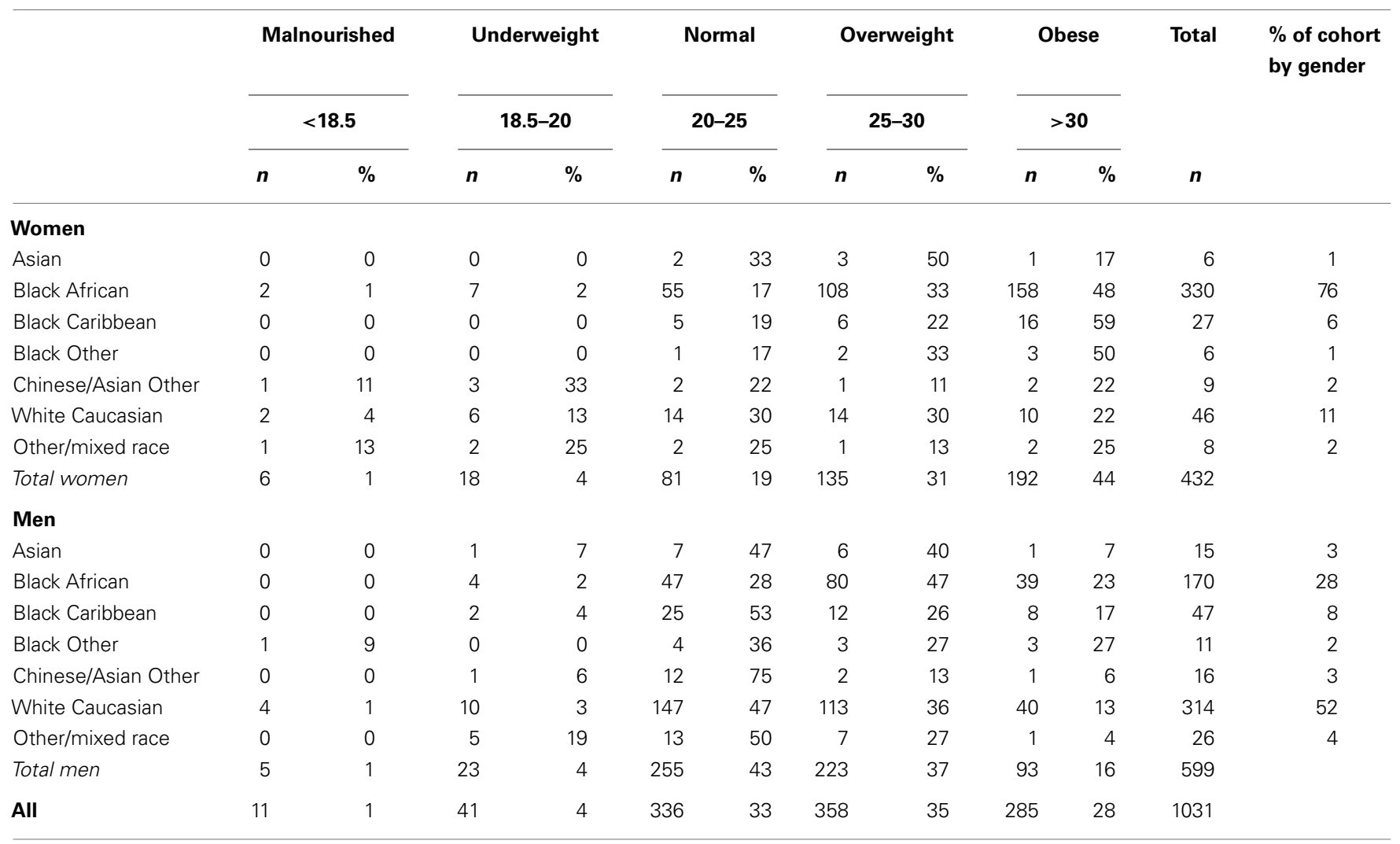

Number (n) and percentage (\%) of HIV-clinic attenders within each BMI category for each defined major ethnic group. "White Caucasian" subjects were mostly of Western European origin.

For females, black ethnicity gave a relative risk (RR) for obesity of 2.2 (95\% confidence interval 1.4-3.6; $P<0.0001$ ). In males, obesity was also associated with black ethnicity, $22 \%$ being obese (RR $1.9,1.3-2.7 ; P=0.001)$, although numbers were smaller (50/228). Conversely, wasting was uncommon in any sub-population; only $11 / 1,031$ (1\%) were wasted, and 52/1031 (5\%) had a BMI of $<20 \mathrm{~kg} / \mathrm{m}^{2}$.

Having demonstrated a significant trend to obesity, predominantly affecting Black African women, we generated five possible explanatory hypotheses (framed as questions):

\section{HYPOTHESIS 1: IS OBESITY IN AFRICAN WOMEN AN EFFECT OF cART?}

Interviews in the subgroup of 50 women from sub-Saharan Africa [principally Uganda (16) and Zimbabwe (10)] revealed that $48 \%$ felt their weight-gain was linked to their therapy (39\% "definite" and 9\% "probable"). However, the observed year-on-year increase in obesity was not associated with an increased proportion of patients receiving cART; $86 \%$ in the 2011-2012 cohort, compared with $83 \%$ in 2001. (Similar values pertained at intermediate 3-year reviews: 75,86 , and $92 \%$ in 2004, 2007, and 2010 respectively.) Furthermore, in the 20112012 cohort, there was no difference between the mean BMI of those on treatment and those not $\left(27.5 \pm 5.4 \mathrm{~kg} / \mathrm{m}^{2}, n=884\right.$ versus $26.9 \pm 5.2, n=147, P=0.21$ ). Finally, there was no association between duration of cART and BMI in simple linear regression analysis $(r=0.020, P=0.59, n=884)$. These data do not therefore support a direct link between obesity and cART.

\section{HYPOTHESIS 2: IS OBESITY THE CONSEOUENCE OF CONCOMITANT CLINICAL FACTORS?}

In order to test this hypothesis, we performed stepwise multiple linear regression analyses relating clinically plausible predictors (age, gender, ethnicity, current smoking status, time since diagnosis, duration of cART, current viral load and CD4 count, glucocorticoid use, alcohol intake, diabetes mellitus, and hepatitis $\mathrm{C}$ ) to current BMI for both recent whole-year reviews (analyzed separately as per section "Materials and Methods"). Very strong associations were found between BMI and gender, black African ethnicity, and smoking history (negatively) (Table 3). Age, CD4 count, and glucocorticoid use also emerged as important positive correlates. Duration of cART (taken as a linear variable) made a weak, but negative, contribution in the latter cohort $(P=0.013)$, and only after "time since diagnosis" was excluded from the model; the two are clearly collinear. Time since diagnosis, viral load, ethanol excess, diabetes, and hepatitis $\mathrm{C}$ did not add predictive power to the model. Route of exposure was considered but excluded because of collinearity. Gender and ethnicity thus emerge as the strongest predictors of BMI, whilst smoking reduces BMI. 
Table 3 | Potential predictors or weight gain; correlates of high BMI

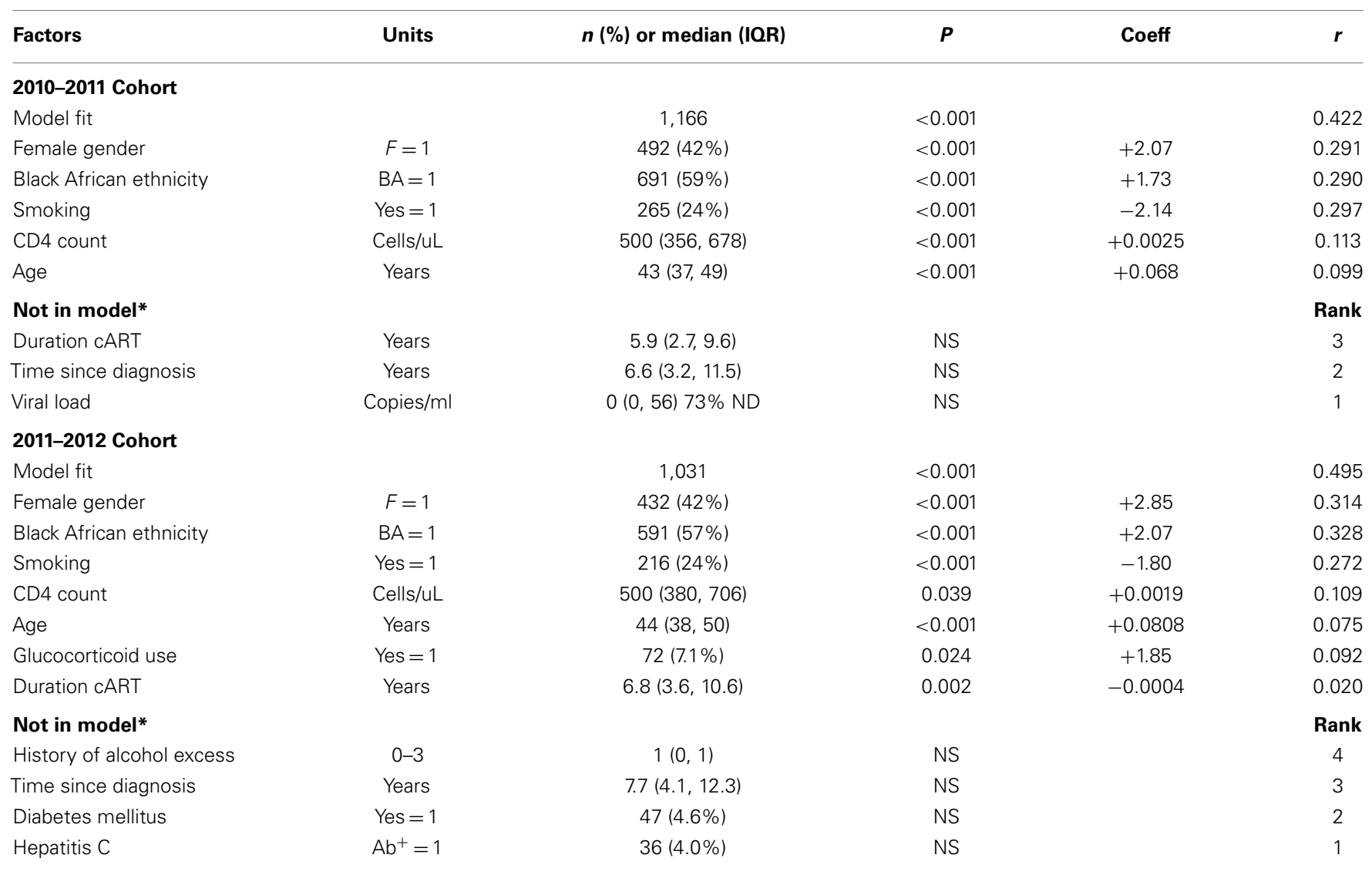

Data are from both 2010-2011 and 2011-2012 cohorts ( $n=1,166$ and 1,031, respectively; 977 subjects participated in both reviews). $P$ values represent probability from

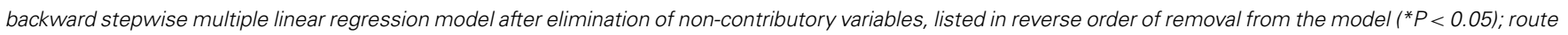

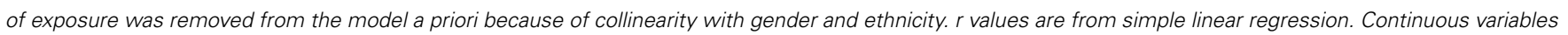

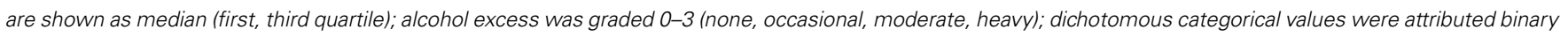
values ( 0 and 1) and are shown as number with attribute (\% of recorded values).

\section{HYPOTHESIS 3: IS OBESITY DRIVEN BY AN UNDERESTIMATION OF WEIGHT?}

Since it has been argued that weight perception differs in women of African origin (28), we investigated the contribution of bodyweight perception to obesity in the subgroup of 50 African women. Most were first-generation immigrants (median duration in the UK 10 years), mostly (86\%) from urban areas. Mean age was 40 years (range 20-60). Weight perception was explored using three complementary modalities. First, using weight in kilograms, subjects expressed a mean value for "usual" weight close to their current weight (Figure 2A, shown normalized to BMI). "Ideal" weights, however, differed between groups, correlating positively with BMI group $(r=0.70, P<0.0001$; Figure 2A). Thus, more obese subjects identified "ideal" body weights in the overweight range according to WHO criteria (mean BMI for ideal weights: $29.1 \mathrm{~kg} / \mathrm{m}^{2}$ ). These values were significantly higher than the "ideal" values given by normal-weight women $\left(23.0 \mathrm{~kg} / \mathrm{m}^{2} ; P<0.0001\right.$, one-way ANOVA).

Verbal descriptors yielded a similar pattern. Subjects usually described themselves with words corresponding to lower nutritional status categories than their WHO BMI category (Table 4).
For example, $40 \%$ of obese subjects described themselves as "normal" weight, and $33 \%$ as "overweight", whilst $47 \%$ of overweight patients used the "normal" designation.

Third, when body shape perception was analyzed using silhouettes corresponding to known BMI values [Series A (39)], obese subjects dramatically underestimated their current level of adiposity, identifying "current" body shape silhouettes corresponding to a mean BMI of $26.2 \mathrm{~kg} / \mathrm{m}^{2}$, whereas their true mean BMI was $35.0 \mathrm{~kg} / \mathrm{m}^{2}$ ( $p=0.0002$, Wilcoxon signed rank test). When asked about "ideal" body shape, both overweight and obese groups identified shapes less obese than their identified current shape with both silhouette series (Figures 2B,C; $P<0.01$ by Wilcoxon signed rank test) but more obese subjects selected fatter "ideal" silhouettes than thinner subjects [Figure 2B (Series A), $r=0.33, P=0.02$; Figure 2C (Series B), $r=0.34, P=0.02$, Spearman]. The "ideal shape" selected by obese subjects corresponded to a mean BMI of $23 \mathrm{~kg} / \mathrm{m}^{2}$, much less than their "ideal weight" $\left(29.1 \mathrm{~kg} / \mathrm{m}^{2}\right)$, demonstrating a significant perceptual gap between body weight and body shape.

The difference between current shape and ideal shape is customarily expressed as a "discrepancy score" (DS, = current - ideal 

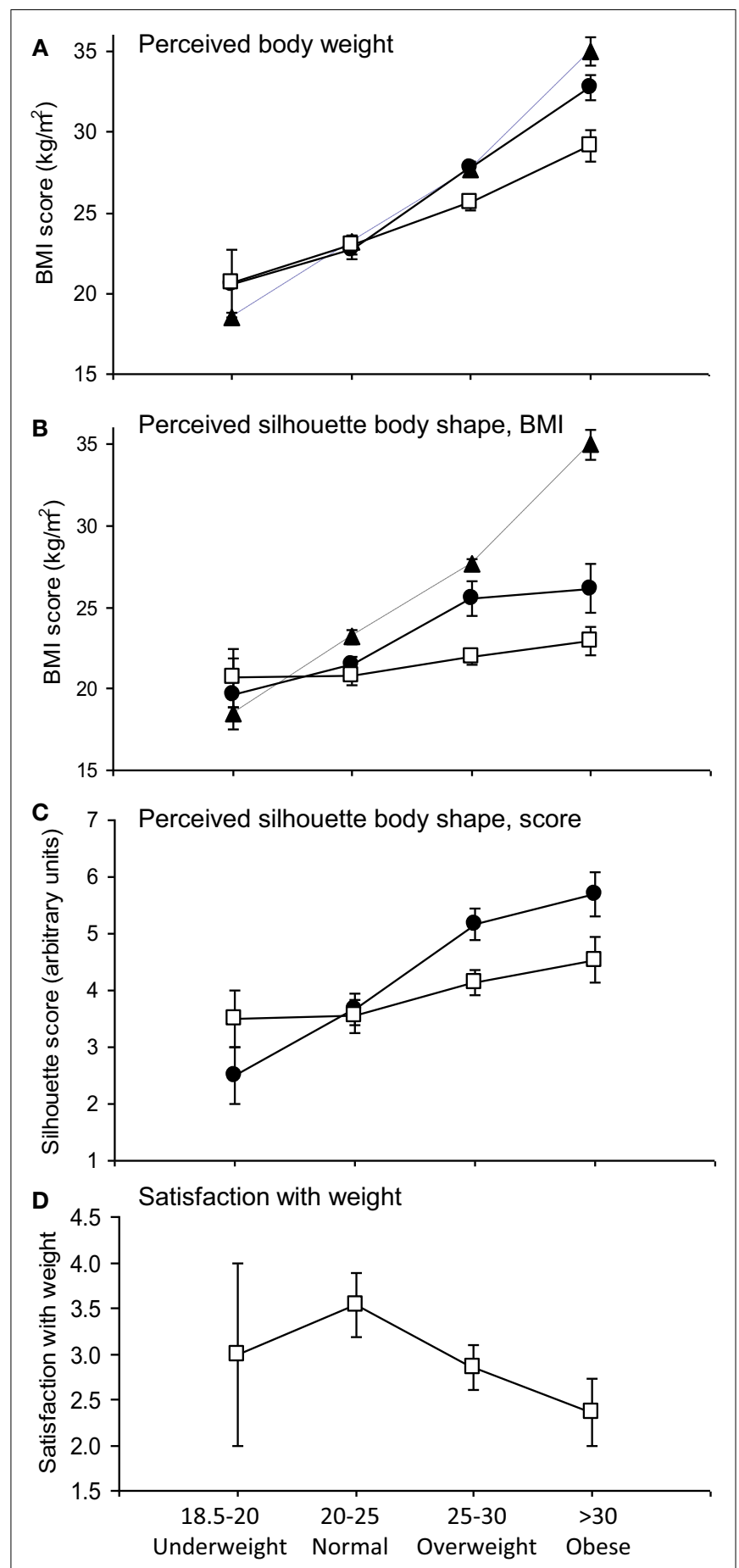

True Nutritional status (BMI, $\mathrm{kg} / \mathrm{m}^{2}$ )

FIGURE 2 | Relationship of perceived and ideal body size to current nutritional status. (A) Perceived body weight: True (filled triangles, dashed line), usual (filled circles), and ideal (open squares) body weight, expressed in kilograms (normalized to BMI) of patients according to current nutritional status category. "True" represents measured values, and "Usual" and "Ideal" were derived from questionnaire responses. (B) Perceived body shape from silhouettes corresponding to known BMI values (Series A) compared to true BMI (filled triangles). Data are shown for perceived

(Continued)

\section{FIGURE 2 | Continued}

"current" shape (filled circles) and "ideal" shape (open squares).

(C) Perceived body shape from numbered silhouettes (Series B) expressed as "current" shape (filled circles) and "ideal" shape (open squares).

(D) Subjects' happiness with current body-weight scored from 1 to 5 (1, very unhappy; 2, unhappy; 3, not bothered; 4, happy; 5 , very happy) according to current BMI category. All data shown are means \pm 1 SEM.

shape) $(41,42)$, which can be taken as a surrogate marker for the drive to lose weight. As expected, and as widely observed in non-HIV populations, this score was greater in those with higher BMI. The intercept-value $(\mathrm{DS}=0)$ corresponding to a threshold for body image dissatisfaction was $26.9 \mathrm{~kg} / \mathrm{m}^{2}$ in this cohort (Figure 3A), a value in the "overweight" range, intermediate between published values for white urban Americans $\left(24.6 \mathrm{~kg} / \mathrm{m}^{2}\right)$ and African-Americans $\left(29.3 \mathrm{~kg} / \mathrm{m}^{2}\right)$ (42). Similarly, those with high DS scores identified themselves with fatter silhouettes (Figure 3B), but their drive to lose weight appeared "blunted" when compared to population-based normative data for Caucasians (41), each DS score corresponding to a silhouette about one score fatter than controls.

Thus all three modalities yielded similar conclusions that more obese women have heavier target weights but underestimate both their current level of obesity and the gap between current and "ideal" body weight, consistent with a reduced drive to lose weight.

\section{HYPOTHESIS 4: IS OBESITY ASSOCIATED WITH A DESIRE TO BE "FATTER"?}

Contrary to the hypothesis that African women are happy to be more obese, increased BMI was associated with a reduction in how happy subjects felt about their body weight, according to the satisfaction score attributed (Figure 2D; $r=0.32, P=0.02$, Spearman). The normal BMI group scored highest for satisfaction, 8/13 $(62 \%)$ describing themselves as "very happy" or "happy" with their weight. In the obese group, only 4/14 (29\%) responded with these scores, whilst $9 / 14$ (64\%) stated they were "unhappy" or "very unhappy" with their weight $(P=0.03$ versus normal BMI group, chi-squared). This dissatisfaction was unrelated to concerns about cardiovascular risk; most women participating (35/50, 70\%) were unaware of other major cardiovascular risk factors.

\section{HYPOTHESIS 5: IS OBESITY THE CONSEOUENCE OF NORMALIZATION TO THE POPULATION OF ORIGIN?}

An alternative hypothesis is that HIV-positive patients are simply "normalizing" to the nutritional demographics of their background population. We therefore compared our observations with the most recent comparable ethnically categorized data, the "2004 Health Survey for England: Health of Ethnic Minorities" (HSE) (38) which includes BMI data on 11,022 UK residents, 5,443 classified by ethnicity. Although this national survey reported high obesity rates in black African women $\left(38 \% \mathrm{BMI}>30 \mathrm{~kg} / \mathrm{m}^{2}\right.$, versus $23 \%$ in the general female population, with a further $31 \%$ overweight), our obesity rates exceeded these values by about $10 \%$ (Figure 4A). Conversely men in our HIV-positive cohort had lower levels of obesity than the general population (Figure 4B). In men, black African ethnicity did not appear to favor obesity, either in 
Table 4 | Descriptions used by subjects to describe body weight according to nutritional status by BMI category.

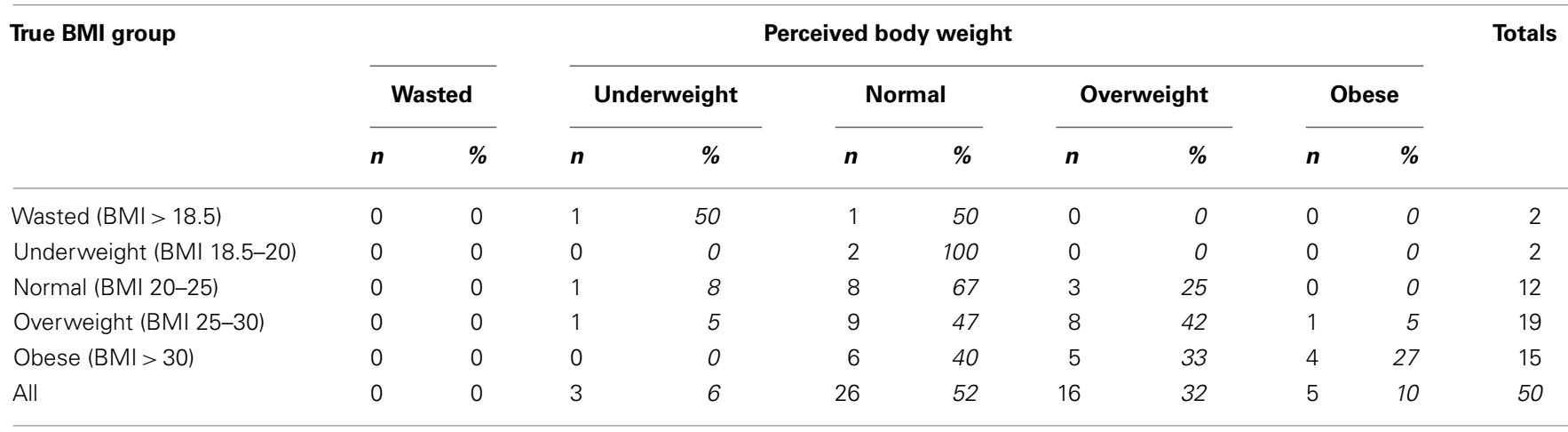

Responses from 50 black African women recruited consecutively from clinic attenders regardless of weight/BMI.
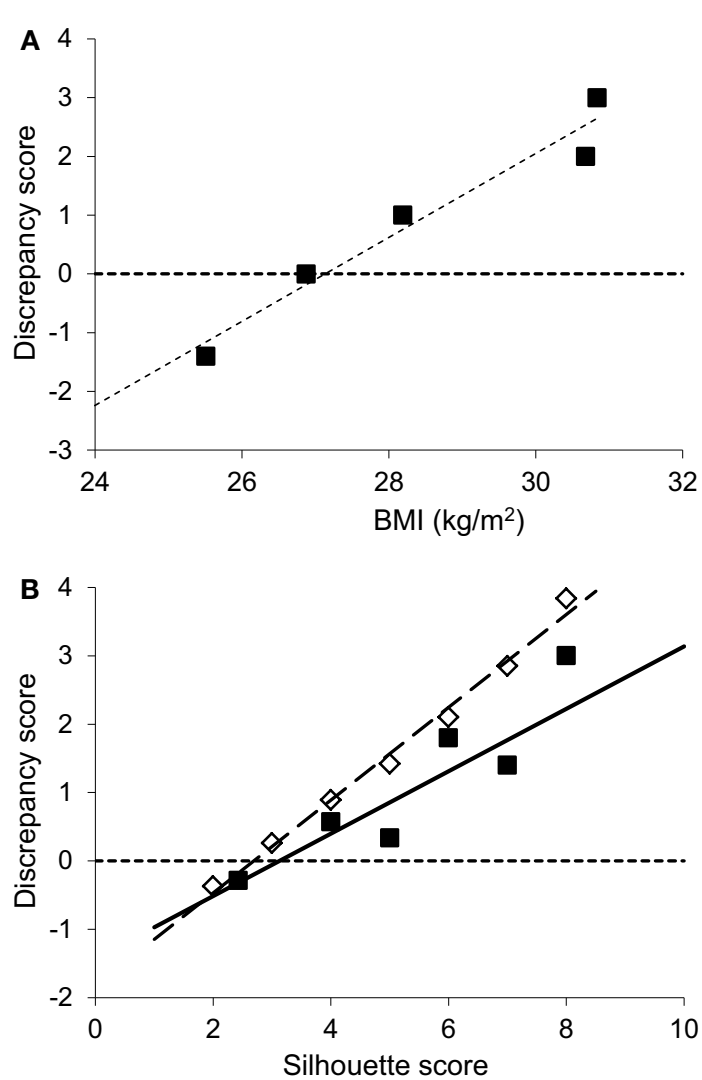

FIGURE 3 | Discrepancy between current and ideal body shape from body shape silhouettes. (A) Discrepancy (current minus ideal) silhouette score groups, shown according to the corresponding current mean BMI for that group (groups with scores 1 and 2 were small so were conflated), showing higher discrepancy scores correspond to higher BMI's ( $r=0.37$, intercept $\left.26.9 \mathrm{~kg} / \mathrm{m}^{2}, P<0.01, n=47\right)$. (B) Filled squares: discrepancy scores by current silhouette score where higher silhouette score indicates greater adiposity $(r=0.61, P<0.001, n=47)$. Comparison is made with normative data (open diamonds) from a large Caucasian population $(n=16,728)(41)$.

our cohort $(P=0.56)$, or in HSE, where obesity rates in black African men were lower than the general population (17 versus $22 \%$ ) (38). It might be argued that data from 2004 do not represent
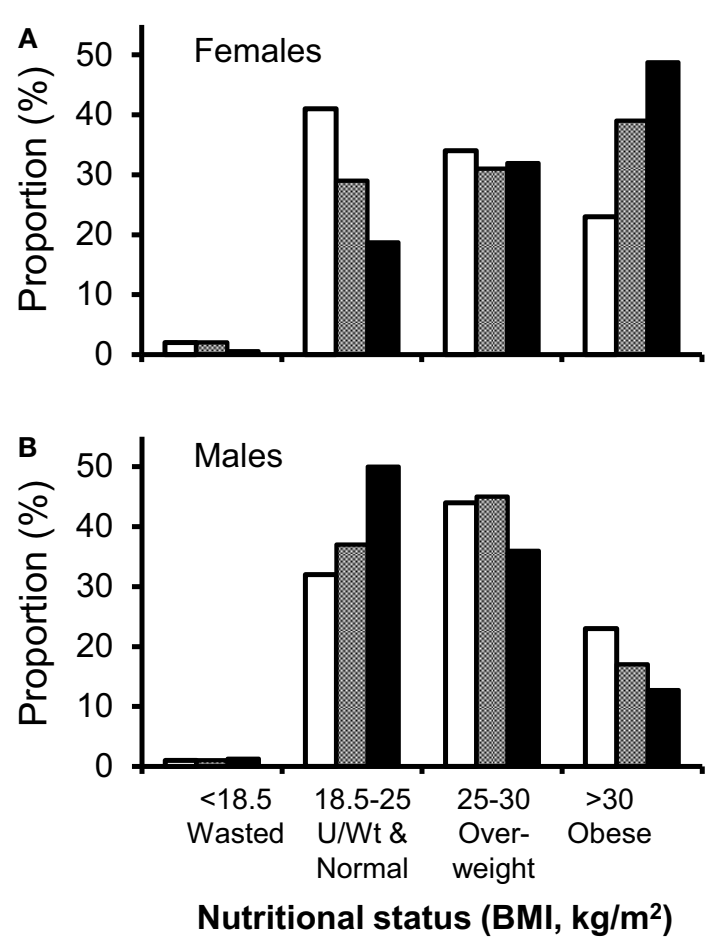

FIGURE 4 | Comparison of nutritional demographics in HIV-clinic attenders to the general population. Distribution between different nutritional status groups for HIV-positive clinic attenders (solid bars) versus the general population (open and hatched bars). (A) Men, general population (open), black African men in general population (shaded), HIV-positive Caucasian males (solid bars), and (B) women, general population (open bars), black African women in general population (shaded), HIV-positive black African women (solid bars). Comparative data (HSE), expressed as percentage of each ethnic group, are from the Health Survey of England ( $n=11,022 ; 5,443$ classified by ethnic group, including 629 black Africans) (38). Note, HSE data did not give subgroup data for white Caucasian populations and were not subdivided at $20 \mathrm{~kg} / \mathrm{m}^{2}$, so

"underweight" and "normal" weight clinic attenders have been conflated to demonstrate comparable data.

a sufficiently contemporaneous comparator; however, more recent national obesity data categorized by ethnicity could not be identified. In order to compensate for this time difference, we compared 
obesity rates in women in England of all ethnicities in 2004 with those in 2011. Rates increased from 23 to $26 \%$ (43) suggesting that time-trends in obesity in the general population, whilst increasing, are unlikely to explain the increase prevalence of obesity seen in our clinic cohort.

\section{DISCUSSION}

Our data strongly support the hypothesis that obesity is increasing in prevalence among HIV-positive patients on treatment, consistent with the paradigm that obesity is "...the latest epidemic" among HIV-infected individuals $(7,8)$. In our clinic-population, the effect was greatest among women of black African origin, $49 \%$ of whom were obese in this study. By contrast, wasting was very infrequent, although, of course, studying an outpatient cohort inevitably excluded acutely unwell in-patients and non-attenders in whom wasting may be more frequent.

We explored several plausible mechanistic hypotheses to explain the increasing prevalence of obesity in this population. Regression analysis identified gender, age and ethnicity as major correlates of this effect, together with a high CD4 count. Smoking was associated with lower BMI, as generally observed. Many women attributed their weight gain to antiretroviral therapy and individual weight-graphs (Figure S3 in Supplementary Material) suggest that weight gain occurs concurrently and progressively during successful treatment. However, this was not corroborated by analysis of duration of cART and BMI (where a weak correlation only emerged after adjusting for other parameters, and then the effect was negative). Not all collinearity could be controlled for; thus it is impossible to dissect duration of cART from era in which CART was started in this fixed time point cohort.

Such observations raise the question as to whether the weightgain seen in this cohort [and others $(2,7,8,11,12)$ ] represents "normal" obesity, or is a variant of "HALS" (10). Certainly there is evidence that ethnicity alters the phenotypic expression of HALS, white race predisposing to lipoatrophy rather than fat accumulation (44). More detailed regional body composition data might clarify this issue, but were not collected here. Although changes in drug selection have resulted in a significantly reduced prevalence of HALS (6), our data suggest that weight-gain data should be monitored assiduously as the cumulative exposure to current agents increases and as new drugs are rolled out.

Gender and ethnicity are associated with obesity in the general population and our data follow similar trends. However, our findings suggest that the African women in this cohort have significantly "overshot" background levels of obesity (49 versus 38\%), suggesting that regression to the norm is not an adequate explanation for the weight-gain seen in patients on treatment. The difficulties finding comparator data have been highlighted and it is hoped that future studies, such as further iterations of the Health Survey of England, will include ethnicity-specific data.

This study clearly has several limitations. First, the population studied has an implicit recruitment-bias toward those successfully adhering to treatment. Second, the silhouettes, although widely used and easy to understand, have coarse gradations, constraining choice, and are ethnically dependent; culturally relevant tools being developed may be more appropriate (45). Silhouette assessment represents a composite of both perceptual and attitudinal elements; more sophisticated tools such as digital morphing may allow additional insights (46). To test the nutritional-programing hypothesis, we included questions relating current obesity to birthweight, but few respondents could answer these questions (data not shown). Collection of detailed body composition and dietary parameters would have enabled further hypothesis-testing. In terms of generalizability, we recognize the wide genetic diversity between different sub-Saharan African populations and the even greater differences, both genetic and cultural, between subSaharan and American-African populations, in whom European ancestry may contribute to obesity; (47) these two groups cannot be conflated into a single category. Reanalysis, excluding Caribbean patients from the category "of-African-origin" did not affect our results, so we believe our results describe a generalizable phenomenon, consistent with observations in other populations (2, $7,8,11,12)$.

Since the major factors associated with this phenomenon, ethnicity, age and gender, are not amenable to intervention, we sought to identify factors which were. Exploring the contribution of bodyweight perception to obesity revealed four major themes. First, obese black African HIV-positive women tended to underestimate current levels of adiposity (this was true for all three modalities tested: numerical weight, word descriptors and body shape silhouettes), similar to a South African cohort (48). Second, obese subjects defined higher "ideal" weights than their thinner counterparts. Third, there was a disparity between weight and shape: obese subjects tended to underestimate the weight loss (in $\mathrm{kg}$ ) required to achieve a certain body shape. Fourth, disparity scores, which reflect the drive to lose weight, were lower in our population than comparator Caucasian populations.

Thus perceptions of obesity/adiposity may tend to promote or maintain weight-gain, but this is not the same as a desire to be fatter; indeed we found the converse was true. Greater adiposity was associated with lower, not higher, levels of satisfaction with current weight; obese patients in this cohort wanted to be thinner than their current weight. Fear of weight loss was not specifically mentioned in interviews but over half of the women surveyed had experienced profound prior illness-associated weight loss. Awareness of cardiovascular risk was low among this group of women and thus not a major motivator for weight loss; this may not be inappropriate as the average predicted 10-year CVD risk (49) for individuals in the obese group (including cholesterol and blood pressure, recorded but not presented here) was only $1.6 \%$.

In conclusion, obesity appears to be a major developing problem among HIV-positive people on treatment, especially women of African origin. Although antiviral therapy was perceived as a contributing factor, we found little evidence to support this hypothesis. Rather we found evidence for a high target "ideal" weight, less dissatisfaction with a larger body shape, and poor awareness of cardiovascular risk in this cohort. These are important factors because they may be amenable to intervention. Although perceptions and attitudes may be difficult to influence, improved patient education and dietetic advice could seek to increase awareness of the propensity to and the risks of obesity. Even small changes may be worthwhile; in other settings (e.g. type2 diabetes), minor reductions in weight can dramatically improve metabolic status (50). 


\section{AUTHOR CONTRIBUTIONS}

Claire L. McCormick performed data collection and analysis; reviewed and approved final manuscript. Arianne M. Francis performed data collection and analysis; helped draft the manuscript. Kim Iliffe helped design the study; performed data collection and analysis; reviewed and approved final manuscript. Helen Webb recruited patients and performed data collection; reviewed and approved final manuscript. Catherine J. Douch performed data collection and analysis; reviewed and approved final manuscript. Mark Pakianathan helped design the study and oversaw data collection; reviewed and approved final manuscript. Derek C. Macallan conceived and designed the study, performed data analysis and drafted and edited the manuscript.

\section{ACKNOWLEDGMENTS}

We are grateful to the staff of the Courtyard Clinic, St George's NHS Trust, London, for their support and assistance and to the patients who participated in this study. We also thank Helen Tate, Alison Barbour, Jun Hua Tan, and Katie Wilkinson for comments on the study design, manuscript, and assistance with data collection and processing. Claire L. McCormick was supported by a grant from Gilead Sciences Ltd.

\section{SUPPLEMENTARY MATERIAL}

The Supplementary Material for this article can be found online at http://www.frontiersin.org/Journal/10.3389/fimmu.2014.00507/ abstract

\section{REFERENCES}

1. Macallan DC, Noble C, Baldwin C, Jebb SA, Prentice AM, Coward WA, et al. Energy expenditure and wasting in human immunodeficiency virus infection. N Engl J Med (1995) 333(2):83-8. doi:10.1056/NEJM199507133330202

2. Hodgson LM, Ghattas H, Pritchitt H, Schwenk A, Payne L, Macallan DC. Wasting and obesity in HIV outpatients. AIDS (2001) 15(17):2341-2. doi:10.1097/ 00002030-200111230-00024

3. Mangili A, Murman DH, Zampini AM, Wanke CA. Nutrition and HIV infection: review of weight loss and wasting in the era of highly active antiretroviral therapy from the nutrition for healthy living cohort. Clin Infect Dis (2006) 42(6):836-42. doi: $10.1086 / 500398$

4. Friis-Moller N, Sabin CA, Weber R, d'Arminio MA, El-Sadr WM, Reiss P, et al. Combination antiretroviral therapy and the risk of myocardial infarction. $N$ Engl J Med (2003) 349(21):1993-2003. doi:10.1056/NEJMoa030218

5. Sabin CA, Worm SW, Weber R, Reiss P, El-Sadr W, Dabis F, et al. Use of nucleoside reverse transcriptase inhibitors and risk of myocardial infarction in HIVinfected patients enrolled in the D:A:D study: a multi-cohort collaboration. Lancet (2008) 371(9622):1417-26. doi:10.1016/S0140-6736(08)60423-7

6. Nguyen A, Calmy A, Schiffer V, Bernasconi E, Battegay M, Opravil M, et al. Lipodystrophy and weight changes: data from the Swiss HIV cohort study, 20002006. HIV Med (2008) 9(3):142-50. doi:10.1111/j.1468-1293.2007.00537.x

7. Crum-Cianflone N, Tejidor R, Medina S, Barahona I, Ganesan A. Obesity among patients with HIV: the latest epidemic. AIDS Patient Care STDS (2008) 22(12):925-30. doi:10.1089/apc.2008.0082

8. Crum-Cianflone N, Roediger MP, Eberly L, Headd M, Marconi V, Ganesan A, et al. Increasing rates of obesity among HIV-infected persons during the HIV epidemic. PLoS One (2010) 5(4):e10106. doi:10.1371/journal.pone.0010106

9. Tate T, Willig AL, Willig JH, Raper JL, Moneyham L, Kempf MC, et al. HIV infection and obesity: where did all the wasting go? Antivir Ther (2012) 17(7):1281-9. doi:10.3851/IMP2348

10. Freitas P, Carvalho D, Santos AC, Matos MJ, Madureira AJ, Marques R, et al. Prevalence of obesity and its relationship to clinical lipodystrophy in HIV-infected adults on anti-retroviral therapy. J Endocrinol Invest (2012) 35(11):964-70. doi:10.3275/8187
11. Hendricks KM, Willis K, Houser R, Jones CY. Obesity in HIV-infection: dietary correlates. J Am Coll Nutr (2006) 25(4):321-31. doi:10.1080/07315724.2006. 10719542

12. Lakey W, Yang LY, Yancy W, Chow SC, Hicks C. Short communication: from wasting to obesity: initial antiretroviral therapy and weight gain in HIV-infected persons. AIDS Res Hum Retroviruses (2013) 29(3):435-40. doi:10.1089/AID. 2012.0234

13. Mulligan K, Harris DR, Monte D, Stoszek S, Emmanuel P, Hardin DS, et al. Obesity and dyslipidemia in behaviorally HIV-infected young women: adolescent trials network study 021. Clin Infect Dis (2010) 50(1):106-14. doi:10.1086/648728

14. Boodram B, Plankey MW, Cox C, Tien PC, Cohen MH, Anastos K, et al. Prevalence and correlates of elevated body mass index among HIV-positive and HIVnegative women in the women's interagency HIV study. AIDS Patient Care STDS (2009) 23(12):1009-16. doi:10.1089/apc.2009.0175

15. Amorosa V, Synnestvedt M, Gross R, Friedman H, MacGregor RR, Gudonis D, et al. A tale of 2 epidemics: the intersection between obesity and HIV infection in Philadelphia. J Acquir Immune Defic Syndr (2005) 39(5):557-61.

16. Karmon SL, Moore RD, Dobs AS, Keruly J, Barnett S, Cofrancesco J Jr. Body shape and composition in HIV-infected women: an urban cohort. HIV Med (2005) 6(4):245-52. doi:10.1111/j.1468-1293.2005.00284.x

17. Comuzzie AG. The emerging pattern of the genetic contribution to human obesity. Best Pract Res Clin Endocrinol Metab (2002) 16(4):611-21. doi:10.1053/ beem.2002.0224

18. Rankinen T, Zuberi A, Chagnon YC, Weisnagel SJ, Argyropoulos G, Walts B, et al. The human obesity gene map: the 2005 update. Obesity (2006) 14(4):529-644. doi:10.1038/oby.2006.71

19. Luke A, Wu X, Zhu X, Kan D, Su Y, Cooper R. Linkage for BMI at 3q27 region confirmed in an African-American population. Diabetes (2003) 52(5):1284-7. doi:10.2337/diabetes.52.5.1284

20. Ranade K, Geese WJ, Noor M, Flint O, Tebas P, Mulligan K, et al. Genetic analysis implicates resistin in HIV lipodystrophy. AIDS (2008) 22(13):1561-8. doi:10.1097/QAD.0b013e32830a9886

21. Walder K, Norman RA, Hanson RL, Schrauwen P, Neverova M, Jenkinson $\mathrm{CP}$, et al. Association between uncoupling protein polymorphisms (UCP2UCP3) and energy metabolism/obesity in pima Indians. Hum Mol Genet (1998) 7(9):1431-5. doi:10.1093/hmg/7.9.1431

22. Bouchard C, Perusse L, Chagnon YC, Warden C, Ricquier D. Linkage between markers in the vicinity of the uncoupling protein 2 gene and resting metabolic rate in humans. Hum Mol Genet (1997) 6(11):1887-9. doi:10.1093/hmg/6.11. 1887

23. Kimm SY, Glynn NW, Aston CE, Damcott CM, Poehlman ET, Daniels SR, et al. Racial differences in the relation between uncoupling protein genes and resting energy expenditure. Am J Clin Nutr (2002) 75(4):714-9.

24. Barker DJ. The developmental origins of well-being. Philos Trans R Soc Lond B Biol Sci (2004) 359(1449):1359-66. doi:10.1098/rstb.2004.1518

25. Eriksson JG, Forsen TJ, Osmond C, Barker DJ. Pathways of infant and childhood growth that lead to type 2 diabetes. Diabetes Care (2003) 26(11):3006-10. doi:10.2337/diacare.26.11.3006

26. Dulloo AG, Jacquet J, Girardier L. Poststarvation hyperphagia and body fat overshooting in humans: a role for feedback signals from lean and fat tissues. Am J Clin Nutr (1997) 65(3):717-23.

27. Schwenk A, Hodgson L, Wright A, Ward LC, Rayner CF, Grubnic S, et al. Nutrient partitioning during treatment of tuberculosis: gain in body fat mass but not in protein mass. Am J Clin Nutr (2004) 79(6):1006-12.

28. Clark RA, Niccolai L, Kissinger PJ, Peterson Y, Bouvier V. Ethnic differences in body image attitudes and perceptions among women infected with human immunodeficiency virus. J Am Diet Assoc (1999) 99(6):735-7. doi:10.1016/ S0002-8223(99)00398-3

29. Furnham A, Baguma P. Cross-cultural differences in the evaluation of male and female body shapes. Int J Eat Disord (1994) 15(1):81-9.

30. Altabe M. Ethnicity and body image: quantitative and qualitative analysis. Int J Eat Disord (1998) 23(2):153-9. doi:10.1002/(SICI)1098-108X(199803)23: 2<153::AID-EAT5>3.0.CO;2-J

31. Rucker CE, Cash TF. Body images, body-size perceptions, and eating behaviors among African-American and white college women. Int $J$ Eat Disord (1992) 12(3):291-9. doi:10.1002/1098-108X(199211)12:3<291::AIDEAT2260120309>3.0.CO;2-A 
32. Powell AD, Kahn AS. Racial differences in women's desires to be thin. Int J Eat Disord (1995) 17(2):191-5. doi:10.1002/1098-108X(199503)17:2<191: :AID-EAT2260170213>3.0.CO;2-Z

33. Mvo Z, Dick J, Steyn K. Perceptions of overweight African women about acceptable body size of women and children. Curationis (1999) 22(2):27-31. doi:10.4102/curationis.v22i2.719

34. Puoane T, Tsolekile L, Steyn N. Perceptions about body image and sizes among black African girls living in Cape Town. Ethn Dis (2010) 20(1):29-34.

35. Cachelin FM, Rebeck RM, Chung GH, Pelayo E. Does ethnicity influence bodysize preference? A comparison of body image and body size. Obes Res (2002) 10(3):158-66. doi:10.1038/oby.2002.25

36. Physical Status: The Use and Interpretation of Anthropometry. Report of a WHO Expert Committee WHO Technical Report Series No. 854. Geneva: World Health Organisation (1995). Available from: http://whqlibdoc.who.int/trs/WHO_TRS_ 854.pdf?ua=1

37. Macallan DC, Noble C, Baldwin C, Foskett M, McManus T, Griffin GE. Prospective analysis of patterns of weight change in stage IV human immunodeficiency virus infection. Am J Clin Nutr (1993) 58:417-24.

38. Becker E, Boreham R, Chaudhury M, Craig R, Deverill C, Doyle M, et al. Health Survey for England 2004. Leeds: Health of Ethnic Minorities (2006).

39. Association CD. The Body Test Material. Toronto: Canadian Dietetic Association (1988).

40. Stunkard AJ, Sorensen T, Schulsinger F. Use of the danish adoption register for the study of obesity and thinness. Res Publ Assoc Res Nerv Ment Dis (1983) 60:115-20.

41. Bulik CM, Wade TD, Heath AC, Martin NG, Stunkard AJ, Eaves LJ. Relating body mass index to figural stimuli: population-based normative data for Caucasians. Int J Obes Relat Metab Disord (2001) 25(10):1517-24. doi:10.1038/sj.ijo.0801742

42. Fitzgibbon ML, Blackman LR, Avellone ME. The relationship between body image discrepancy and body mass index across ethnic groups. Obes Res (2000) 8(8):582-9.

43. Craig RM. Health Survey for England - 2011, Health, Social Care and Lifestyles. London: Health \& Social Care Information Centre (2012). Available from: http://www.hscic.gov.uk/catalogue/PUB09300

44. Mallal SA, John M, Moore CB, James IR, McKinnon EJ. Contribution of nucleoside analogue reverse transcriptase inhibitors to subcutaneous fat wasting in patients with HIV infection. AIDS (2000) 14(10):1309-16. doi:10.1097/ 00002030-200007070-00002

45. Pulvers KM, Lee RE, Kaur H, Mayo MS, Fitzgibbon ML, Jeffries SK, et al. Development of a culturally relevant body image instrument among urban African Americans. Obes Res (2004) 12(10):1641-51. doi:10.1038/oby.2004.204
46. Johnstone AM, Stewart AD, Benson PJ, Kalafati M, Rectenwald L, Horgan G. Assessment of body image in obesity using a digital morphing technique. J Hum Nutr Diet (2008) 21(3):256-67. doi:10.1111/j.1365-277X.2008. 00862.x

47. Cheng CY, Reich D, Coresh J, Boerwinkle E, Patterson N, Li M, et al. Admixture mapping of obesity-related traits in African Americans: the atherosclerosis risk in communities (ARIC) study. Obesity (2010) 18(3):563-72. doi:10.1038/oby. 2009.282

48. Hurley E, Coutsoudis A, Giddy J, Knight SE, Loots E, Esterhuizen TM. Weight evolution and perceptions of adults living with HIV following initiation of antiretroviral therapy in a South African urban setting. S Afr Med J (2011) 101(9):645-50.

49. Anderson KM, Odell PM, Wilson PW, Kannel WB. Cardiovascular disease risk profiles. Am Heart J (1991) 121(1 Pt 2):293-8. doi:10.1016/0002-8703(91) 90861-B

50. Petersen KF, Dufour S, Befroy D, Lehrke M, Hendler RE, Shulman GI. Reversal of nonalcoholic hepatic steatosis, hepatic insulin resistance, and hyperglycemia by moderate weight reduction in patients with type 2 diabetes. Diabetes (2005) 54(3):603-8. doi:10.2337/diabetes.54.3.603

Conflict of Interest Statement: The authors declare that the research was conducted in the absence of any commercial or financial relationships that could be construed as a potential conflict of interest.

Received: 14 June 2014; paper pending published: 01 September 2014; accepted: 29 September 2014; published online: 13 November 2014.

Citation: McCormick CL, Francis AM, Iliffe K, Webb H, Douch CJ, Pakianathan M and Macallan DC (2014) Increasing obesity in treated female HIV patients from SubSaharan Africa: potential causes and possible targets for intervention. Front. Immunol. 5:507. doi: 10.3389/fimmu.2014.00507

This article was submitted to HIV and AIDS, a section of the journal Frontiers in Immunology.

Copyright (C) 2014 McCormick, Francis, Iliffe, Webb, Douch, Pakianathan and Macallan. This is an open-access article distributed under the terms of the Creative Commons Attribution License (CC BY). The use, distribution or reproduction in other forums is permitted, provided the original author(s) or licensor are credited and that the original publication in this journal is cited, in accordance with accepted academic practice. No use, distribution or reproduction is permitted which does not comply with these terms. 